\title{
The Natura 2000 Biogeographical Process
}

\author{
Neil McIntosh and Tamsin Burbidge \\ ECNC-European Centre for Nature Conservation and ECNC Land \& Sea Group \\ PO Box 90154, 5000 LG Tilburg, The Netherlands \\ Corresponding author: Neil McIntosh <McIntosh@ecnc.org>
}

Received 2 June 2014; Accepted 27 January 2015;

Publication 19 March 2015

\section{Preface}

The Natura 2000 Biogeographical Process was launched by the European Commission in 2011 to assist Member States in managing Natura 2000 as a coherent ecological network. This article provides the background, purpose and core messages of the Process, details the strategic content, aims and opportunities and describes both the current participation and the future plans.

\section{Background and Purpose}

The Natura 2000 Biogeographical Process was launched by the European Commission in 2011 to assist Member States in managing Natura 2000 as a coherent ecological network. The primary purpose of the Natura 2000 Biogeographical Process is to assist Member States to meet legal obligations under the nature directives with respect to the favourable conservation status of habitats and species of community interest. Through the Natura 2000 Biogeographical Process, a key aim is to ensure that Member States and expert stakeholders are enabled to realise collaborative networking events, associated information sharing and cooperative knowledge building activities, linked to common strategic priorities. The EU 2020 Biodiversity Strategy calls for a step change in efforts to halt the loss of biodiversity and to restore essential services that a healthy natural environment provides.

Journal of Green Engineering, Vol. 4, 261-270.

doi: 10.13052/jge1904-4720.441

(C) 2014 River Publishers. All rights reserved. 


\section{Core Messages of the Process}

The following points highlight key features of the Natura 2000 Biogeographical Process:

- Participation in the Natura 2000 Biogeographical Process is voluntary;

- The Process provides a valuable means to work collectively towards achieving the legal obligations of the Nature Directives;

- The Process offers a practical framework for networking, sharing information and experience and building knowledge about the most effective ways to reach and maintain favourable status for habitats and species of European Community importance - this includes opportunities to identify and promote the multiple benefits linked to such actions;

- The Process focuses on practical habitat management and restoration activities and provides a framework to share best practices, compare approaches, build contacts, exchange information and build new knowledge;

- The Process is supported by follow-up networking events designed to further build practical knowledge and capacity, along with a dedicated Natura 2000 Platform to communicate and share information.

\section{Strategic Content}

As responsibility for implementation of Natura 2000 and ensuring progress towards the EU's Biodiversity Strategy targets lies with Member States, they are key actors in the Natura 2000 Biogeographical Process. Also, there are significant opportunities through the Process to improve mobilisation of expert networks and inputs from other key stakeholders. This is important to benefit from the direct experience of Natura 2000 practitioners, expert stakeholders and Member States' representatives with specific responsibilities for implementation of Natura 2000. This underlines the strategic and operational importance of the Process and the integrated inputs required from diverse actors.

In the Natura 2000 network, as in the Strategy, the needs of biodiversity are central, but not isolated - for example, by taking an ecosystem-based approach (i.e. recognizing the full array of interaction within an ecosystem rather than focusing on one specific issue, species or ecosystem service), it is possible to ensure that nature (and therefore Natura 2000) continues to contribute to growth at local, regional, national and European levels. Working through the cooperation mechanisms provided by the Process, this means that: 
- The inputs of Member States and expert stakeholders are central to defining the forms of collaboration required to achieve the 2020 targets.

- Collaborative actions should focus on nature's many processes and functions to improve habitat condition and generate multiple benefits, including social prosperity and welfare.

- There is opportunity to reflect and think collectively about practical ways to improve the favourable conservation status of habitats and species and to learn from Article 17 reporting experience - this includes utilizing the Process to, for example:

- Identify the forms of collaboration appropriate for agreed common priorities, including exploring scope for potential LIFE or Interreg project proposals;

- Discuss, agree and set conservation objectives at biogeographical level;

- Define favourable reference values for conservation status at different levels within a biogeographical region.

Therefore, the Strategy captures the common objectives and specifies the key targets to be met - for example, to build understanding about how EU 2020 BD Strategy Target 1 is interpreted. Working with expert stakeholders in the NGO community, over the last 20+ years, significant gains in ecology knowledge, information and practical management experience have been acquired about Natura 2000. However, especially with regard to strengthening Natura 2000 as a coherent ecological network, there is scope to generate measurable improvements about how this knowledge and experience can be collectively developed and collaboratively applied. Cumulatively, improved nature conservation management practices will enable greater progress to be achieved towards the 2020 Biodiversity Strategy goals and targets. In this way, the Process can increasingly be utilized to guide participants towards "common directions".

\section{Aims and Opportunities}

To achieve progress within the strategic context, it is essential that there is clear and shared understanding about what is already known, what has to be achieved and what actions require to be developed together to safeguard biodiversity in Europe. The Process provides practical means to exchange the information, experience and knowledge that is required to identify and define common solutions and develop cooperative actions, which can be delivered to 
ensure progress towards the EU 2020 Biodiversity targets. Specifically, within the Natura 2000 Biogeographical Process, there are opportunities to generate better integrated ecosystem-based management approaches, through mobilizing greater inputs from strategic stakeholders and increasing participation from practitioners. There are support opportunities to network (for example, through workshops or working groups) that generate recommendations for practical Natura 2000 management, matched by shared commitments for future actions.

Working with established Steering Committees and experts in each biogeographical region is designed to foster greater focus on strategic targets for example, explore how to use Article 17 data more proactively and build common understanding about core strategic policy areas such as interpretations of favourable conservation status and favourable reference values. Also, through the Process, there is an important opportunity to catalyse change, by increasing practical know-how and insights on the basis of learning from pilot studies: this includes, benefiting from experience gains realized through LIFE (\& other) projects and monitoring results (including Article 17 reporting) to increase synergies; at the same time, for example, through improved information sharing about management practices and approaches per habitat type, and promoting identified best practices for specific Natura 2000 management issues. The aim is to continue to develop the Natura 2000 Biogeographical Process with greater focus on strategic outcomes achieved through supporting a range of practical management cooperative actions that strengthen the implementation of Natura 2000.

\section{Current Participation}

One of the key features of the Natura 2000 Biogeographical Process is that participation is voluntary. Involvement to-date has been very positive. The data presented in the tables and in Figure 1 has been compiled from all biogeographical regions since the start of the process in 2011 - these include all policy makers, experts, consultants, site managers, NGO representatives and other stakeholders involved in either the coordination of the process, the Steering Committee, expert contributions to the Background Document, preparatory workshops and seminars.

The information used to compile this overview of the Natura 2000 biogeographical process has been extracted from the Natura 2000 Platform database, developed and maintained by ECNC. As can be seen, the main interest in the Process is predominantly around the location of the central administration. The high number of participants from North, West and Central European countries 
Table 1 Number of active participants in the process by biogeographical region

\begin{tabular}{lc}
\hline Biogeographical Region & Active Participants \\
\hline Alpine & 329 \\
Atlantic & 255 \\
Boreal & 194 \\
Continental & 110 \\
Macaronesian & 2 \\
Mediterranean & 161 \\
Marine & 2 \\
\hline
\end{tabular}

This table shows the number of active participants involved in the process by Biogeographical region. These figures include members of the Steering Committees, experts contributing to background documents, and participants in the various events (workshops, seminars, ad hoc meetings, networking meetings, etc). A totals row is not included in this table, because many individuals participate in more than one Biogeographical process. This information is also illustrated in the following pie chart:

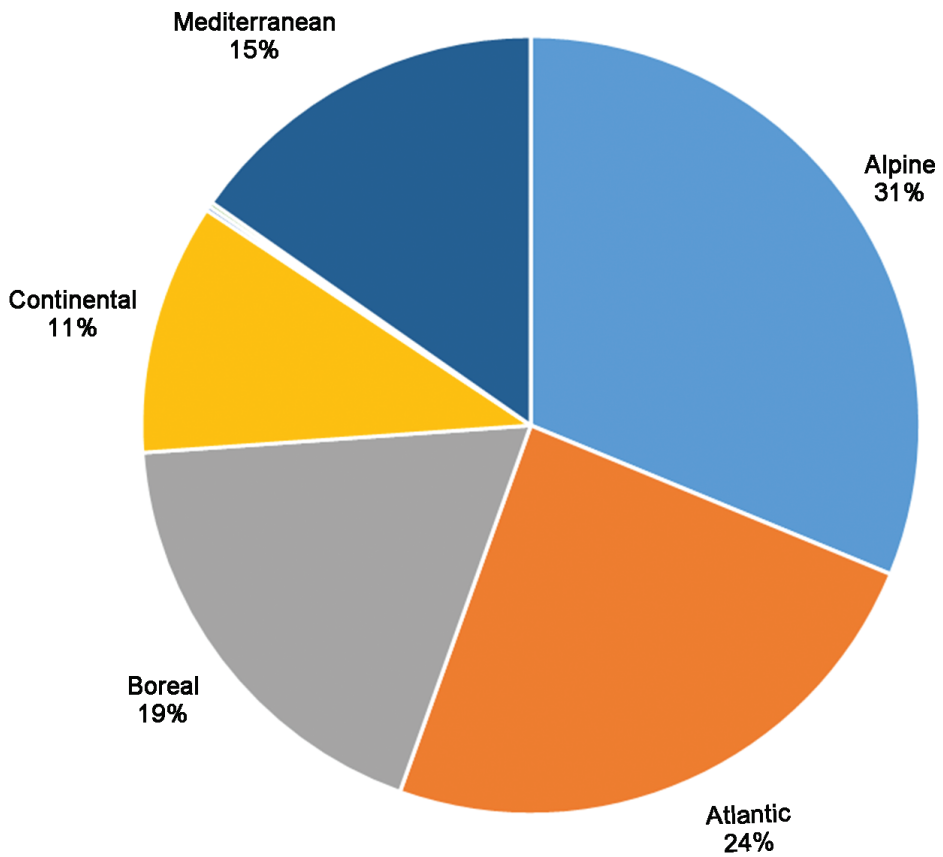

Figure 1 Number of active participants in the Natura 2000 biogeographical process since 2011.

reflects the fact that the first three Biogeographical Regions involved in the Process are Boreal, Atlantic and Alpine. The Mediterranean Biogeographical Process started in May 2014, and there has been significant interest and levels 
of participation. The sectors from which participants have been engaged are as follows:

\begin{tabular}{lc}
\hline Sector & \# People \\
\hline Agriculture & 35 \\
Environment & 398 \\
Financial & 5 \\
Fisheries & 4 \\
Forest & 46 \\
Hunting & 7 \\
Industry & 3 \\
Nature conservation & 784 \\
Planning & 108 \\
Site management & 64 \\
Tourism & 5 \\
Transport and infrastructure & 8 \\
Water & 32 \\
\hline Total & 1499 \\
\hline
\end{tabular}

There is growing cross-sector involvement in the Process, which is fundamentally required when discussing challenges and issues related to Natura 2000 and, in particular, ecosystem-based management approaches. Through the Process, there are new opportunities to define common priorities and take collaborative actions based on the integrated needs and perspectives of diverse stakeholders.

\section{Progress in Sharing of Knowledge for Different Ecosystems}

In general there has been a great deal of progress in the sharing of knowledge since the beginning of the Natura 2000 Biogeographical Process. Each biogeographical region has its own specific needs, but also scope to address common themes, such as access to information about project funding opportunities.

Within the Boreal region much progress in development of discussions and sharing of knowledge has already been made. Many seminars and workshops have been organised including a wetlands restoration workshop, which allowed for the sharing of strategies and experiences between Member States and expert stakeholders. Also, the exchange of best practices for forestry between Member States and stakeholders is currently receiving attention. Further plans for sharing of knowledge include a seminar to address common issues within grassland habitats and workshops about good practices. 
Within the Atlantic region progress includes developments in the problem of Nitrogen deposition and diffuse pollution of water. A knowledge exchange meeting was organised to determine: CL's/per habitat and nitrogen ceilings needed to reach FCS. Translation of the OBN/government report on nitrogen deposition and diffuse pollution of water (including problems and measures) into English has also been carried out. Evaluating utility of AERIUS model from the Netherlands in other communities is ongoing and will result in the circulation of information about the model to all Member States. Further actions to be taken include promoting the development of a mobile app to assist the public to be aware of Natura 2000 sites and provide information including for instance (common) species and Nitrogen deposition. This will include a meeting of Member States to identify existing IT applications and how these can be more widely developed and applied.

Much progress has been made with the sharing of knowledge in the Alpine region including the establishment of a sustainable forum and workshops with field trips (every 2 years) to share knowledge on river and lake restoration and maintenance: this series of networking and knowledge-building events will also provide scope to discuss common issues on the impacts of, for example, hydropower and conservation status. This links to other current activities, including animminent EC guidance document on hydropower and Natura 2000: a draft guidance paper on flood prevention and maintenance works for river ecosystems is currently in preparation and the work of the Alpine Process participants for Natura 2000 habitats and species in their Biogeographical region is contributing to that. Further actions for other ecosystems include raising awareness of grassland habitat conservation issues by organizing events and sharing information on both grassland conservation and ecosystem services.

\section{Future Plans}

Following the success of the first seminars (Boreal Biogeographic region in May 2012, Alpine Biogeographical region in November 2013, Atlantic Biogeographical region in December 2013 and Mediterranean Region in May 2014), the Natura 2000 Biogeographical Process continues, with further thematic 'Kick-off seminars' and 'Review seminars' being planned. Each seminar will be informed by background information on the conservation status and needs of the selected habitat types and species: a list of related habitat groups, crosscutting issues and problems whose solutions should directly contribute to achieving favourable conservation status will also be addressed. 
In addition, the seminars will be organised at the level of biogeographical regions at intervals which take stock of the results of the thematic events in the region. Follow-up actions, identified as being most useful to Process stakeholders, can be further developed through networking and cooperation under a new proposed Natura 2000 Biogeographical Networking Programme. The follow-up actions can take the form of conferences, workshops, expert meetings, or study visits.

Hosted by national or regional actors (rather than lead countries), the Seminars will be supported, organized and facilitated by the EC's contractor, under a technical assistance contract to provide added value opportunities that progress the favourable conservation status of habitats and species of Community interest. The Seminars and follow-up networking events will aim to result in a jointly agreed list of recommendations and priority actions identified by Member States and expert networks for follow-up in-depth cooperation, networking and collaborative action in respective regions and, where appropriate, also between regions.

The results of the Seminars and networking events will continue to be shared on the Natura 2000 Platform. As the content of the Platform expands with greater volumes of relevant Natura 2000 information, it will continue to be developed as a web-based tool for networking, dialogue building and exchanging information on conservation objectives and measures between all actors involved in the Process.

\section{Biographies}

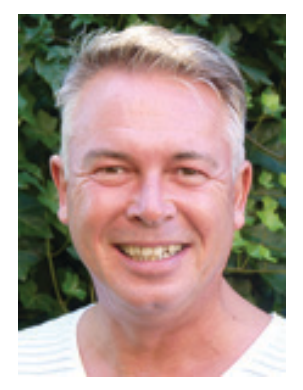

Neil McIntosh studied English Language \& Literature, Politics and Linguistics, graduating with an MA (awarded with merit) from the University of Edinburgh in 1988. He is a qualified project management practitioner, trainer and assessor of training courses. Neil has worked in the public, private and 
voluntary sectors in the fields of environment, natural heritage, health and business development. Living in the Netherlands for almost 10 years, he is fluent in Dutch. Currently, Neil is the Deputy Executive Director and Head of Strategy and Innovation for ECNC- European Centre for Nature Conservation.

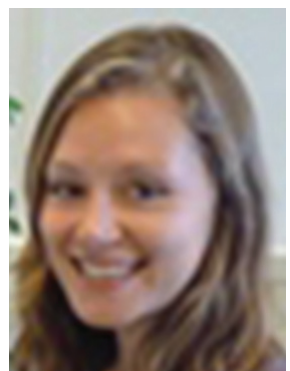

Tamsin Lucy Burbidge graduated from the University of Manchester in June 2009 with a BSc. in Zoology with Industrial Experience (Hons.). She successfully completed an MSc. in Biology at the University of Leiden, the Netherlands. Tamsin continues to live in the Netherlands and has been working as volunteer at ECNC- European Centre for Natura Conservation, based in Tilburg, for almost one year. She has worked as a research assistant in Europe and Africa on various aspects of zoology and has completed research internships on conservation, behavioural and population biology. 
